\title{
The characteristics of the chosen mycotoxins and their toxic influence on the human and animal metabolism
}

\author{
Katarzyna Łazicka, Sławomir Orzechowski*
}

Department of Biochemistry, Faculty of Agriculture and Biology Warsaw University of Life Sciences - SGGW ul. Nowoursynowska Warsaw, Poland; *Corresponding Author: slawomir_orzechowski@sggw.pl

Received 23 December 2009; revised 10 March 2010; accepted 12 April 2010.

\begin{abstract}
Mycotoxins are toxic secondary metabolites of fungi belonging mainly to the Aspergillus, Penicillium and Fusarium genera. They can be formed in various agricultural produce in specific conditions. These natural and zootoxic chemical compounds cause an array of diseases in people and animals, i.e., mycotoxicoses. Depending on the type and dose, mycotoxins may cause liver, kidney, and lung cancers, as well as damage to the immune system, pathological changes in the nervous system, and reproduction disorders. Many mycotoxins disrupt digestion process, cause vomiting, nausea, anorexia, skin irritation and dermatitis, and even haemorrhages. A significant threat to the health of animals and people can be observed in the case of major infestation of crop ears from which foodstuff or feed are then produced. The ear infestation is facilitated by a suitable humidity and temperature during the growing season or while harvesting and storing the agricultural produce, which enhances the growth of mycotoxin-producing fungi. Suitable agricultural treatment, crop rotation, proper storing of crops in the conditions of limited humidity after the harvest as well as regular chemical analyses of the content of mycotoxins minimize their consumption and, accordingly, decrease the threat caused by these substances to the human and animal health.
\end{abstract}

Keywords: Toxicology; Mycotoxins; Mycotoxicoses

\section{INTRODUCTION}

Mycotoxins are low-molecular-weight secondary metabolites produced by moulds. These metabolites constitute various groups of chemical compounds which may cause diseases or even death of an organism. However, not all chemical compounds produced by fungi are mycotoxins. The term 'mycotoxin' was first coined in 1962 after an incident in which almost 100,000 turkeys died. It was stated that the cause of such a high death rate of turkeys was the process of feeding them with peanut meal contaminated with the secondary metabolites of fungi of the Aspergillus flavus genus [1]. Currently, approximately 400 compounds described as mycotoxins are known, dozens of which are hazardous for the health of people and animals. Mycotoxins as chemical substances are not only difficult to be identified, but also difficult to be classified. The most important groups of mycotoxins are as follows: aflatoxins, ergot alkaloids, fumonisins, ochratoxins, trichothecenes, zearalenone and derivatives, epipolythiodioxopiperazines (ETP).

Based on the intensity and action time, the symptoms of mycotoxin poisoning are classified as acute, subacute, or chronic poisoning. Acute poisonings have a violent course and a clear reaction of the organism (e.g. the death of turkey population). On the other hand, chronic and subacute poisonings are caused by low doses of mycotoxins entering an organism for a long time, and they may cause e.g. liver cancer (aflatoxins) or kidney disorders (ochratoxins). Mycotoxins are found more often in those world regions in which less effective methods of eliminating fungi in the plant production and storing are applied (Africa, Asia, South America), as well as in significantly undernourished regions and where the inspection of food as far as the content of mycotoxins is concerned is irregular.

Mycotoxins could be divided into 2 groups: the group produced as a result of plant diseases in the vegetation season and the group of metabolites formed during improper storing of grain after the harvest. Mycotoxins have adverse effects on plants, the biological productivity of agroecosystems, the quality of surface waters, as well as on grassland and woodland ecosystems. Their harmful effect on plants is based mainly on the inhibi- 
tion of germination of seeds and growth of plants, particularly the growth of roots and root hair.

\section{THE INFLUENCE OF THE CHOSEN MYCOTOXINS ON THE HUMAN AND ANIMAL HEALTH}

\subsection{Aflatoxins}

Aflatoxins are highly carcinogenic compounds as far as fish, warm-blooded animals, and people are concerned. The disease caused by these mycotoxins is called aflatoxicosis and it can lead even to death. The symptoms of chronic aflatoxicosis are liver cancer, immune system damage, as well as other ailments. Liver, which is the key organ in the mycotoxin detoxication, is the organ exposed most to the influence of one of the forms of aflatoxins, i.e., aflatoxin $\mathrm{B}_{1}\left(\mathrm{AFB}_{1}\right)$. Moreover, aflatoxins may cause certain negative changes in the lungs. The development of lung cancer was observed in the workers inhaling dust contaminated with $\mathrm{AFB}_{1}$ during the production of peanuts [2]. The amount of aflatoxins eaten with food is lower in the developed countries than in the developing ones. This is connected mainly with the regular food inspections being performed in order to detect aflatoxins, which in poorer countries, where food deficiency is present, are very rare or are not carried out at all. The high consumption of aflatoxins with food contributes to the development of primary liver cancer 2 to 5 times more often than in the developed countries [3].

Dogs are particularly sensitive to aflatoxins, as even relatively low doses of these mycotoxins in feed (0.5-1 mg per $1 \mathrm{~kg} \mathrm{b.m}$.) may cause their death. At doses ranging from $0.05-0.3 \mathrm{mg} / \mathrm{kg}$ b.m. of aflatoxins, provided for 6 to 8 weeks, vomiting, depression, hepatitis, coma, and jaundice are observed in dogs. Dogs are exposed to the influence of aflatoxins most often due to the introduction of grain contaminated with aflatoxins into feed production, which for this reason cannot be used for the production of food for people [4].

The extent and intensity of poisoning with aflatoxins depend on age, sex, body mass, diet, resistance to infections, presence of other mycotoxins, as well as on pharmacological agents in diet. Due to the differences in sensitivity to aflatoxins in tests performed on animals, it is difficult to explain the influence of aflatoxins on the human organism. Mycotoxin $\mathrm{AFB}_{1}$ becomes active under the influence of cytochrome P-450, present in liver microsomes, in the presence of molecular oxygen and $\mathrm{NADPH}$. On the other hand, the active form of $\mathrm{AFB}_{1}$ may bond with DNA or proteins [5]. The $\mathrm{AFB}_{1}$-DNA adducts cause the transversion mutation GC: TA.

Aflatoxins are found in the marketed animal feeds all over the world, particularly in the North and South Americas. Birdseed was the most contaminated feed among all the types of products for domestic animals probably due to the basic materials of this feed, which are grains and hazelnuts. As much as $25 \%$ of birdseed samples were contaminated with over $100 \mu \mathrm{g} \mathrm{AFB}_{1} / \mathrm{kg}$, which indicates the potential threat to the health of birds. Feeds for dogs and cats contain small amounts of aflatoxins. Almost all the feed samples that these mycotoxins were found in, contained less than $20 \mu \mathrm{g} \mathrm{AFB} / \mathrm{kg}$ [6]. Such a low level of aflatoxins in the feed does not cause any symptoms of acute poisoning. However, the possible future influence of these mycotoxins on the animal metabolism should not be ignored.

\subsection{Ergot Alkaloids}

The chemical compounds belonging to this group of mycotoxins are produced as a mixture of alkaloids in sclerotia of the strains of Claviceps - Claviceps purpurea, which are common pathogens of various grass species ears. The consumption of ergot or its spores was found to be connected with the occurrence of diseases even in the antiquity. In people, the disease known as ergotism occurs after the consumption of products made of grain containing significant amounts of sclerotia, usually as bakery products. Usually two types of ergotism are diagnosed, i.e., gangrenous and convulsive (Saint Anthony's Fire). The gangrenous type ergotism causes significant ischaemia of nose, ears, fingers and toes, which leads to dry gangrene, whereas the convulsive ergotism shows itself in the changes in behaviour, hypersensitivity, convulsions, and muscle tremor [7].

Penitrem A, which belongs to the group of ergot alkaloids, affects the functioning of the central nervous system probably by the interaction with neurotransmitters such as e.g. $\gamma$-aminobutyric acid (GABA) [8].

In animals the clinical symptoms of ergotism are as follows: dry gangrenes, ulcerations, necroses, blindness, convulsions, hypersensitivity and ataxia, and lactation inhibition [6]. A number of ergot alkaloids cause contractions of smooth muscles (e.g. uterus, blood vessels). Among farm animals, sheep, pigs, poultry, and cattle are exposed the most to the influence of these mycotoxins.

\subsection{Fumonisins}

Fumonisins occur in the natural environment in at least three forms: B1, B2, and B3. They are found mainly in feed and food produced from maize [9]. Their influence on the living organisms is diverse; they may cause the development of cancer in humans and animals together with other mycotoxins (intensifying their negative action) $[10,11]$. In horses and rabbits, fumonisins cause leukoencephalomalacia $[12,13]$, and they disrupt sphingol- 
ipid metabolism by the inhibition of (dihydro)ceramide synthesis, causing the accumulation of sphinganine in tissues, serum, and urine. The sphinganine accumulation is responsible for the most of adverse effects of these mycotoxins. The decrease in the sphingolipid complex has a negative effect on the functions of a part of the membrane proteins, such as e.g. folic acid transmitter [14] and contributes to the occurrence of nervous system disease symptoms [15].

\subsection{Ochratoxin}

Among the toxins produced by the Aspergillus and Penicillum species, ochratoxin A (OTA) has a significant meaning from the toxicological and economic points of view. This mycotoxin is formed mainly as a result of improper storing of grain. The most important adverse changes caused by the consumption of food contaminated with ochratoxin A are: kidney and liver damage and immunosuppressive action [16]. Ochratoxin $A$ at the level of cellular metabolism affects the enzymes connected with the metabolism of phenylalanine and causes the inhibition of the mitochondrial synthesis of ATP [17] and acceleration of the peroxidation of lipids [18]. Due to the constitution of ochratoxin A (halogen derivative of phenol), the action of this mycotoxin may also result in the modification of bases constituting the nucleic acids, which may cause mutations and contribute to the development of carcinogenic diseases in the organisms exposed to its influence [19].

\subsection{Trichothecenes}

The name 'trichothecenes' includes almost 200 various compounds characterised as mycotoxins, synthesised mainly by fungi from the Fusarium family found on infested ears. The most important and the most commonly occurring representatives of this group of mycotoxins are deoxynivalenol (DON, vomitoxin), nivalenol (NIV), diacetoxyscirpenol (DAS), and T-2. The typical disease symptoms after the consumption of trichothecenes are: vomiting, lack of appetite, diarrhoea, haemorrhages, the nervous and immune systems disorders, and in case of direct contact dermatitis is observed. Trichothecenes are exceedingly strong inhibitors of the protein synthesis in eukaryotes. They inhibit all its stages: initiation, elongation, and termination. Trichodermin was identified as the first metabolite of the trichothecenes group and its influence on the metabolism consists in the inhibition of peptidyl transferase [20]. Trichodermin inhibits peptidyl transferase through competing with it for the binding site on a ribosome [21].

Among the naturally occurring trichothecenes, T-2 and diacetoxyscirpenol seem to be the most significant ones in the studies on their toxicity in animals. The cy- totoxic influence of these mycotoxins on organisms is based on their negative influence on the immune system, manifesting itself in the decreased resistance to infection with other pathogenic microorganisms. As the final effect, a wide range of gastrointestinal, dermatological and neurological symptoms are observed after the consumption of these mycotoxins by animals [22]. In people, T-2 and diacetoxyscirpenol cause alimentary aleukia. The symptoms of this disease are: dermatitis, vomiting, and hematopoietic tissue disorders. The acute phase results in oral cavity necrosis, nosebleed, vaginal bleeding, and the nervous system disorders. Trichothecene mycotoxins induce also asthma and allergenicity [23].

\subsection{Zearalenone}

The biological activity of zearalenone (ZEA) metabolites is high. It can be generally stated that they act oestrogenlike, though their actual toxicity is low. The $\mathrm{LD}_{50}$ of zearalenone in rats is $10 \mathrm{~g} / \mathrm{kg}$, whereas in guinea pigs it is $5 \mathrm{~g} / \mathrm{kg}$. For this reason, the more appropriate name than mycotoxin for this group of compounds is phytoestrogen (or mycoestrogen). Zearalenone or its derivatives have been patented as oral contraceptives for women, or a drug preventing postmenopausal osteoporosis [24]. The link between the consumption of mouldy grain and hyperestrogenism in pigs has been observed since 1920 . After the administration per os of even minor doses of zearalenone to the sexually immature sows, oestrus-like symptoms without the tolerance reaction and the increase in the mass of certain parts of the reproductive system of the examined sows were observed [25]. In dogs, the studied concentrations of ZEA caused disruptions in reproduction, miscarriages, and testicular atrophy and pathological changes in the reproductive system in males [26,27]. Based on the results of epidemiological studies performed in Canada and Scandinavia, it was stated that the risk for human health after the consumption of zearalenone is not high. The recommended safe intake of zearalenone is estimated at the level of 0.05 $\mu \mathrm{g} / \mathrm{kg}$ b.m. daily. The level of zearalenone in consumables is not checked. The presence of ZEA in diet may cause various interactions with metabolic processes in the organism, and its presence in diet together with other important mycotoxins, such as fumonisins or trichothecenes, is potentially a pathogenic factor. The manifestations of this action may be allergies or the influence on the immune system of animals and people [28].

\subsection{Epipolythiodioxopiperazine ETP}

Characteristic features of the chemical structure of mycotoxins of the ETP group are the presence of disulphide bridge that largely conditions their high reactivity and adverse influence, and the presence of at least 1 aromatic 
acid radical [29]. The most thoroughly characterized mycotoxin from this group is gliotoxin, which is at the same time a drug used e.g. in the treatment of non-alcoholic fatty liver disease. Its action is based on the inhibition of the activity of the nuclear factor $\kappa \mathrm{B}(\mathrm{NF}-\kappa \mathrm{B})$ and activation of apoptosis through the inhibition of mitochondrial ATP synthesis, which leads to the hyperpolarisation of mitochondrial membranes. Apoptosis was provoked by gliotoxin in various cells of the immune system (macrophages, lymphocytes T) [30,31]. Gliotoxin inhibits also the activity of reverse transcriptase, which may be used in the treatment of viral infections in people and animals [32].

Due to its structure, gliotoxin as well as the remaining mycotoxins of the ETP group may take part in the oxidation and reduction reactions in cells, which may cause the formation of reactive oxygen species (ROS) and is, beside the creation of disulfide bridges with proteins, the second main cause of a significant toxicity of this group of mycotoxins observed in animals and people. Table 1 presents the groups of mycotoxins which are the most harmful to the organism, together with the chosen disease symptoms they cause.

\section{METHODS OF LIMITING THE POISONING WITH MYCOTOXINS}

The production of mycotoxins by various species of fungi occurring on agricultural produce happens frequently. These fungi may grow on various plants and agricultural materials at an appropriate humidity and temperature. In the case of agricultural produce, the level of contamina- tion changes by the year, depending on the weather and other environmental factors. For example, aflatoxin is us ually hazardous during dry years, as plants are then weaker and become more susceptible to damage caused by insects and other mechanical injuries. Therefore, it is important to use a proper cultivation technology in such cases: proper fertilization, watering, gathering the crop residue from the field (mainly from crops and monocottyledon weeds), and using fungicides (usually only seed dressing before seeding is performed in the conventional and integrated agriculture). A significantly increased level of mycotoxins in agricultural produce is observed in the case of using non-plough methods of cultivation and direct seeding in comparison to plough cultivation, although in favourable weather conditions this effect is not very visible. Mycotoxins in agricultural produce may appear only after noticing the growth of mould, however not all moulds produce mycotoxins and the production does not take place in all atmospheric conditions. Therefore, an important element limiting the contamination with mycotoxins is constant monitoring of agricultural produce first and then of the agricultural materials and food in order to eliminate excessively contaminated material from subsequent stages of production of food and animal feed.

Depending on the level of contamination with mycotoxins, agricultural produce may be:

1) completely destroyed (significant contamination),

2) destined for the production of feed for animals (contamination threatens human health and life),

3) passed as fit for the production of food for people (trace amount of mycotoxins or their lack).

Table 1. The list of adverse effects of the chosen mycotoxins.

\begin{tabular}{|c|c|c|}
\hline Name & Toxicity class to IARC* & Symptoms/ disease entity \\
\hline Aflatoxins & I & $\begin{array}{l}\text { aflatoxicosis, primary liver cancer, lung neoplasm, lung cancer, failure of the immune system, } \\
\text { vomiting, depression, hepatitis, anorexia, jaundice, vascular coagulation }\end{array}$ \\
\hline Ergot alkaloids & - & $\begin{array}{l}\text { ergotism, gangrene, abortion, convulsions, lactation suppression, hypersensitivity, ataxia, } \\
\text { smooth muscle contractions, extensive saliva production, vomiting }\end{array}$ \\
\hline Ochratoxins & II B & renal diseases, nephropathy, anorexia, vomiting, intestinal haemorrhage, tonsillitis, dehydration \\
\hline Trichothecenes & - & $\begin{array}{l}\text { nausea, vomiting, haemorrhages, anorexia, alimentary toxic aleukia, failure of the immune } \\
\text { system, infants' lung bleeding, increased thirst, skin rash }\end{array}$ \\
\hline ETP & - & $\begin{array}{l}\text { failure of the immune system, susceptibility to fungal infections, facial eczema, liver diseases, } \\
\text { skin and nail necroses }\end{array}$ \\
\hline
\end{tabular}

* IARC - International Agency for Research on Cancer 
Moreover, it has to be kept in mind that giving contaminated feed to susceptible animals may lead to the decrease in the speed of their growth, development of diseases, or even to death. Foodstuffs produced from meat or milk of animals that were previously fed with feed contaminated with mycotoxins, may contain cumulated mycotoxins, e.g. ochratoxin A present in the feed for pigs is accumulated in the tissue of fattening pigs [33]. Furthermore, biotransformations of mycotoxins are also frequently observed in animals fed with the feed contaminated with mycotoxins, e.g. aflatoxins $\mathrm{AFB}_{1}$ eaten by cows with feed undergo biochemical reactions to aflatoxin $\mathrm{M}_{1}$ that is then found in milk.

People who eat properly, avoiding foodstuffs contaminated with moulds, are not exposed to mycotoxins. The symptoms caused by the consumption of high amount of mycotoxins are seldom found in the developed countries. Currently used methods of storing agricultural produce and their processing, as well as production of food aiming at the maximum limitation of development of moulds and inactivation or bounding of the already existing mycotoxins have contributed to this fact. Actions that contribute to the limitation of mould development at various stages of food production are based on: preservation or pasteurization of food, and roasting of grains at a high temperature, which unfortunately may have adverse nutritional effects, i.e., the formation of stable free radicals. On a small scale ozonization is used, which by inhibiting the development of moulds decreases the level of e.g. aflatoxins and trichothecenes in food materials [34]. The limitation of the development of moulds is possible also by adding preservatives and bioactive substances such as e.g. benzoic, acetic, or propionic acids $[35,36]$ to foodstuffs and feeds. On the other hand, the process of lactic fermentation is an example of the use of microorganisms to decrease the level of mycotoxins in feeds and foodstuffs. During the production of silages, the lactic fermentation bacteria contribute to the biotransformation of mycotoxins into metabolites which are not harmful to animals, and the lowered $\mathrm{pH}$ successively inhibits the development of mould spores. The decrease in the amount of mycotoxins and in the extent of infestation with moulds in the agricultural produce may be achieved with the use of simple methods, even by sifting grains, since screenings (damaged and poorly developed caryopses) are often more infested with moulds and hence potentially contaminated with mycotoxins to a higher degree than the fully developed grains [37]. Positive effects in the reduction of the chosen mycotoxins are produced by rinsing grains, e.g. with $1 \mathrm{M}$ solution of sodium carbonate and distilled water, since often the infestation with moulds and the mycotoxins themselves are localized on the grain surface
$[38,39]$. However, such treatment of grains requires drying at further stages of their processing, which puts the producers of feeds and foodstuffs at risk of making additional costs.

Feed and foodstuff producers often use bioactive substances such as: antioxidants (vitamin A, C, E, selenium) $[40,41]$, chosen amino acids (leucine, isoleucine, valine, tyrosine, phenylalanine) [42], and polyunsaturated fatty acids $[15,43]$ as diet supplements. Apart from increasing the nutritive value and safety of feeds and foodstuffs by completing the diet with vitamins, exogenous amino acids, or necessary unsaturated fatty acids, these substances minimize the adverse effects of the chosen mycotoxins (e.g. T-2) on the human and animal organism.

\section{SUMMARY}

In terms of their chemical composition, mycotoxins belong to compounds with a diversified constitution and properties. They are produced by numerous species of moulds, which makes it difficult to detect them in food. The most important groups of mycotoxins are as follows: aflatoxins, ergot alkaloids, fumonisins, ochratoxins, trichothecenes, zearalenones, and epipolythiodioxopiperazines. They have diverse toxic effects on animals and cause among others cancers, protein synthesis inhibition, failure of the immune system, skin and mucosa irritation, as well as other disorders. Usually mycotoxins enter an organism per os due to the consumption of food contaminated with them, through the respiratory system, or by direct contact with the skin. In the developing countries, the contamination of food and animal feed with mycotoxins is a significant problem. In the industrialized countries, appropriate techniques meant for harvesting and storing of agricultural produce and for the production of food and animal feed have been developed, which has significantly limited the occurrence of mycotoxicoses in people and animals A considerable problem to be solved is the unification of regulations and standards concerning the contents of certain mycotoxins all over the world, as well as the elaboration of cheap and reliable diagnostic tests for monitoring the contamination of agricultural produce with mycotoxins at all stages of the food production chain.

\section{REFERENCES}

[1] Forgacs, J. (1962) Mycotoxicoses - the neglected diseases. Feedstuffs, 34(18), 124-134.

[2] Hayes, R.B., van Nienwenhuise, J.P., Raatgever, J.W. and Ten Kate, F.J.W. (1984) Aflatoxin exposure in the industrial setting: An epidemiological study of mortality. Food and Chemical Toxicologyi, 22(1), 39-43. 
[3] Henry, S.H., Bosch, F.X. and Bowers, J.C. (2002) Aflatoxin, hepatitis and worldwide liver cancer risks. In: DeVries, J.W., Trucksess, M.W. and Jackson, L.S., Eds., Mycotoxins and Food Safety. Kluwer Academic/Plenum Publications, New York, 229-320.

[4] Stenske, K.A., Smith, J.R., Newman, S.J., Newman, L.B. and Kirk, C.A. (2006) Aflatoxicosis in dogs and dealing with suspected contaminated commercial foods. Journal of the American Veterinary Medical Association, 228(11), 1686-1691.

[5] Eaton, D.L. and Gallagher, E.P. (1994) Mechanisms of aflatoxin carcinogenesis. Annual Review of Pharmacology and Toxicology, 34, 135-172.

[6] Maia, P.P. and Pereira Bastos de Siqueira, M.E. (2002) Occurrence of aflatoxins B1, B2, G1 and G2 in some Brazilian pet foods. Food Additives and Contaminants, 19(12), 1180-1183.

[7] Bennett, J.W. and Bentley, R. (1999) Pride and prejudice: The story of ergot. Perspectives in Biology and Medicine, 42(3), 333-355.

[8] Puschner, B. (2002) Mycotoxins. Veterinary Clinics: Small Animal Practice, 32(2), 409-419.

[9] Tekiela, A. (2007) Różnice w stopniu infekcji ziarna kukurydzy przez grzyby Fusarium spp. a skażenia przez mikotoksyny w uprawie mieszańców kukurydzy modyfikowanych genetycznie i ich form wyjściowych w warunkach polskich. Kosmos, 56(3-4), 301-305.

[10] Peraica, M., Radic, B., Lucic, A. and Pavlovic, M. (1990) Toxic effects of mycotoxins in humans. Bulletin of the World Health Organization, 77(9), 754-766.

[11] Pozzi, C.R., Correa, B., Xavier, J.G., Direito, G.M., Orsi, R.B. and Matarazzo, S.V. (2001) Effects of prolonged oral administration of fumonisin B1 and aflatoxin B1 in rats. Mycopathologia, 151(1), 21-27.

[12] Bucci, T., Hansen, D.K. and LaBorde, J.B. (1996) Leucoencephalomalacia and hemorrhage in the brain of rabbits gavaged with mycotoxin fumonisin B1. Journal of Natural Toxins, 4(1), 51-52.

[13] Marasas, W.F.O., Kellerman, T.S., Gelderblom, W.C.A., Coetzer, J.A.W., Thiel, P.G. and van Der Lugt, J.J. (1988) Leukoencephalomalacia in horse induced by fumonisin B1 isolated from Fusarium moniliforme. The Onderstepoort Journal of Veterinary Research, 55(4), 197-203.

[14] Stevens, V.L. and Tang, J. (1997) Fumonisin $B_{1}$-induced sphingolipid depletion inhibits vitamin uptake via the glycosylphosphatidylinositol-anchored folate receptor. Journal of Biological Chemistry, 272(29), 18020-18025.

[15] Sadler, T.W., Stevens, V.L., Merrill, A.H., Sullards, M.C., Wang, E. and Wang, P. (2002) Prevention of fumonisin $\mathrm{B}_{1}$-incuced neural tube defects by folic acid. Teratology 66(4), 169-176.

[16] Kuiper-Goodman, T. and Scott, P.M. (1989) Risk assessment of the mycotoxin ochratoxin A. Biomedical and Environmental Sciences, 2(3), 179-248.

[17] Meisner, H. and Meisner, P. (1981) Ochratoxin A, an in vivo inhibitor of renal phosphoenolpyruvate carboxylase. Archives of Biochemistry and Biophysics, 208(1), 146151.

[18] Rahimtula, A.D., Bereziat, J.C., Bussacchini-Griot, V. and Bartsch, H. (1988) Lipid peroxidation as a possible cause of ochratoxin A toxicity. Biochemical Pharmacology, 37(23), 4469-4475.
[19] Dai, J., Wright, M.W. and Manderville, R.A. (2003) Ochratoxin a forms a carbon-bonded c8-deoxyguanosine nucleoside adduct: Implications for $\mathrm{c} 8$ reactivity by a phenolic radical. Journal of the American Chemical Society, 125(3), 3716-3717.

[20] Wei, C.M., Campbell, I.M., McLaughlin, C.S. and Vaughn, M.H. (1974) Binding of trichodermin to mammalian ribosomes and its inhibition by other 12,13-epoxytrichothecenes. Molecular and Cellular Biochemistry, 3(3), 215-219.

[21] Feinberg, B. and McLaughlin, C.S. (1989) Biochemical mechanism of action of trichothecene mycotoxins. In: Beasley, V.R., Ed., Trichothecene mycotoxicoses: Pathoph-Ysiologic Effects, CRC Press, Boca Raton, 1, 2735.

[22] Rotter, B.A., Prelusky, D.B. and Pestka, J.J. (1996) Toxicology of deoxynivalenol (vomitoxin). Journal of Toxicology and Environmental Health, 48(1), 1-34.

[23] Pestka, J.J., Yike, I., Dearborn, D.G., Ward, M.D.W. and Harkema, J.R. (2008) Stachybotrys chartarum, trichothecene mycotoxins, and damp building - related illness: New insights into a public health enigma. Toxicological Sciences, 104(1), 4-26.

[24] Hidy, P.H., Baldwin, R.S., Greasham, R.L., Keith, C.L. and Mc-Mullen, J.R. (1977) Zearalenone and some derivatives: production and biological activities. Advances in Applied Microbiology, 22, 59-82.

[25] Gajęcki, M. (2002) Zearalenone - undesirable substancje in feed. Polish Journal of Veterinary Sciences, 5(2), 117122.

[26] Gajęcka, M., Jakimiuk, E., Polak, M., Otrocka-Domagala, I., Janowski, T., Zwierzchowski, W., Obremski, K., Zielonka, L., Apoznanski, J. and Gajęcki, M. (2004a) Zearalenone applied per os provides adverse effects in structure of chosen parts of bitch reproductive system. Polish Journal of Veterinary Sciences, 7(1), 59-66.

[27] Gajęcka, M., Jakimiuk, E., Skorska-Wyszynska, E., Zielonka, L., Polak, M., Paluszewski, A., Rybarczyk, L. and Gajęcki, M. (2004b) Influence of zearalenone mycotoxicosis on selected immunological, haematological and biochemical indexes of blood plasma in bitches. Polish Journal of Veterinary Sciences, 7(3), 175-180.

[28] Gajęcki, M., Gajęcka, M., Zielonka, Ł., Jakimiuk, E. and Obremski, K. (2006) Zearalenone as a potential allergen in the alimentary tract - a review. Polish Journal of Food and Nutrition Sciences, 15(3), 263-268.

[29] Gardiner, D. Waring, P. \& Howlett, B. (2005) The epipolythiodioxopiperazine (ETP) class of fungal toxins: Distribution, mode of action, functions and biosynthesis. Microbiology, 151(Pt 4), 1021-1032.

[30] Pahl, H.L., Krauss, B., Schulze-Osthoff, K., Decker, T.E., Traenckner, B.-M., Vogt, M., Myersfl, Ch., Parksfl, T., Warring, P., Miihlbacher, A., Czernilofiky, A.P. and Baeuerle, P.A. (1996) The immunosuppressive fungal metabolite gliotoxin specifically inhibits transcription factor NF-kB. Journal of Experimental Medicine, 183(4), 1829-1840.

[31] Wright, M., Issa, R., Smart, D., Trim, N., Murray, G., Primrose, J., Arthur, M., Iredale, J. and Mann, D. (2001) Gliotoxin stimulates the apoptosis of human and rat hepatic stellate cells and enhances the resolution of liver fibrosis in rats. Gastroenterology, 121(3), 685-698. 
[32] Rodriguez, P.L. and Carrasco, L. (1992) Gliotoxin: Inhibitor of poliovirus RNA synthesis that blocks the viral RNA polymerase 3Dpol. Journal of Virology, 66(4), 1971-1976.

[33] Stoev, S.D., Paskalev, M., MacDonald, S. and Mantle, P.G. (2002) Experimental one year ochratoxin A toxicosis in pigs. Experimental and Toxicologic Pathology, 53(6), 481-487.

[34] Proctor, A.D., Ahmedna, M., Kumar, J.V. and Goktepe, I. (2004) Degradation of aflatoxins in peanut kernels/flour by gaseous ozonation and mild heat treatment. Food Additives and Contaminants, 21(8), 786-793.

[35] Hazan, R., Levine, A. and Abeliovich, H. (2004) Benzoic acid, a weak organic acid food preservative, exerts specific effects on intracellular membrane trafficking pathways in Saccharomyces cerevisiae. Applied and Environmental Microbiologyi, 70(8), 4449-4457.

[36] Lambert, R.J. and Stratford, M. (1999) Weak-acid preservatives: Modelling microbial inhibition and response. Journal of Applied Microbiology, 86(1), 157-164.

[37] Leung, M.C.K., Diaz-Llano, G. and Smith, T.K. (2006) Mycotoxins in pet food: A review on worldwide prevalence and preventative strategies. Journal of Agricultural and Food Chemistry, 54(26), 9623-9635.

[38] Trenholm, H.L., Charmley, L.L., Prelusky, D.B. and Warner, R.M. (1992) Washing procedures using water or sodium carbonate solutions for the decontamination of three cereals contaminated with deoxynivalenol and zearalenone. Journal of Agricultural and Food Chemistry, 40(11), 2147-2151.

[39] Trenholm, H.L., Charmley, L.L., Prelusky, D.B. and Warner, R.M. (1991) Two physical methods for the decontamination of four cereals contaminated with deoxynivalenol and zearalenone. Journal of Agricultural and Food Chemistry, 39(2), 356-360.

[40] Atroshi, F., Rizzo, A., Biese, I., Lindberg, L.A. and Saloniemi, H. (2002a) Effects of feeding T-2 toxin and deoxynivalenol on DNA and GSH contents of brain and spleen of rats supplemented with vitamin $\mathrm{E}$ and $\mathrm{C}$ and selenium combination. Journal of Animal Physiology and Animal Nutrition, 180(74), 151-167.

[41] Atroshi, F., Rizzo, A., Westermarck, T. and Ali-Vehmas, T. (2002b) Antioxidant nutrients and mycotoxins. Toxicology, 180(2), 151-167.

[42] Cavan, K.R., MacDonald, E.J. and Smith, T.K. (1988) Potential for dietary amino acid precursors of neurotransmitters to overcome neurochemical changes in acute T-2 toxicosis in rats. Journal of Nutrition, 118(7), 901907.

[43] Pestka, J.J., Zhou, H.R., Jia, Q. and Timmer, A.M. (2002) Dietary fish oil suppresses experimental immunoglobulin a nephropathy in mice. Journal of Nutrition, 132(2), 261-269. 